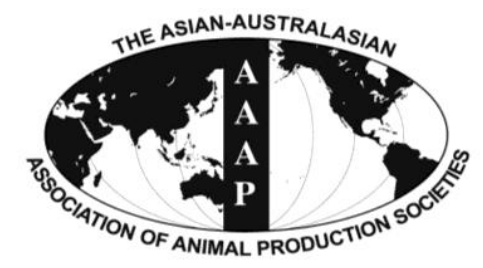

Asian-Aust. J. Anim. Sci.

Vol. 25, No. $5: 717$ - 724

May 2012

www.ajas.info

http://dx.doi.org/10.5713/ajas.2011.11366

\title{
General Behaviors and Perching Behaviors of Laying Hens in Cages with Different Colored Perches
}

\author{
D. H. Chen and J. Bao* \\ College of Animal Science and Technology, Northeast Agricultural University, Harbin 150030, China
}

\begin{abstract}
Color is one of the perch properties. This study was conducted to investigate the general behaviors and perching behaviors in laying hens under different group size (stocking density), and to understand the perch color (black, white or brown) preference of hens during the night. A total of 390 Hyline Brown laying hens was used, and randomly allocated to three treatments: individual group (G1), group of four hens (G4), and group of eight hens (G8), respectively. There were 30 replicates in each group. The hens in G1, G4 and G8 groups were put into the test cages in which three colored perches were simultaneously provided and allowed for four days of habituation in the new cages. Hens behaviors were recorded using cameras with infrared light sources for the following periods: 8:00 to 10:00; 14:00 to $16: 00 ; 19: 00$ to $21: 00 ; 23: 30$ to $0: 30$ on the fifth day after transferring the birds into the test cages. The behaviors of hens in every time period were collected and analyzed, and hens positions on the test perches during mid-night were recorded. The results showed that, group size (stocking density) had significant effect on most of the general behaviors of laying hens except exploring behavior. There were great differences in most of the general behaviors during different time periods. In the preference test of perch color during night, the hens showed no clear preference for white, black or brown perches. For perching behaviors, perching time and frequency of transferring from one perch to another was higher on black perches than on white or brown perches in individual groups. In G4 groups, the hens spent more time on white perches during daytime and more frequent transferring during night compared with black or brown perches. The frequency of jumping upon and down from white perches was higher in G8 groups. It can be concluded that although the group sizes in the cage significantly affected most of the general behaviors, we found that no preference of perch color was shown by the caged laying hens in the different group sizes tested in this study. (Key Words: Perch Color, Laying Hen, Preference, Behavior)
\end{abstract}

\section{INTRODUCTION}

Color is one of the factors in the housing environment. Birds have been shown to have a different spectral sensitivity curve (Prescott and Wathes, 1999), and are more sensitive to the red end of the color spectrum than humans (Manser, 1996). In the hypothalamus of poultry, there are light receptors of the retina, which will reflect differently to photo stimulation of different wavelength light (Foster and Follett, 1985; Lewis and Morris, 2000). It has been suggested that this more sophisticated apparatus for color vision may mean that hens have better vision than humans (King-Smith, 1971), and that their spatial acuity and color perception may be more heavily compromised in dim

\footnotetext{
* Corresponding Author: J. Bao. College of Animal Science and Technology, Heilongjiang Ba-Yi Agricultural University, Daqing 163319, China. Tel: +86-459-6819002, Fax: +86-459-4819002, E-mail: jbao1961@ sina.com

Submitted Oct. 13, 2011; Accepted Dec. 12, 2011; Revised Jan. 30, 2012
}

lighting (Prescott and Wathes, 2002). Because of the particularity of birds' vision, we may surmise that the behavior patterns may be different under different color conditions in housing systems.

The intensive housing system of poultry has been criticized, especially for laying hens in cages. It is believed that hens restricted in conventional cages without being able to freely perform natural behaviors would be under poor welfare conditions. Dawkins and Hardie (1989) suggested the behavior patterns of hens were related to the distance among hens. Moreover, Hughes and Duncan (1972) reported feather pecking of laying hens was found to increase with the group size.

Providing perch can increase the use of vertical space and decrease the density on the floor (Newberry, 1995), and give hens the opportunity to perform natural behaviors (Hughes and Elson, 1977). Taylor et al. (2003) suggested that the white colored perches may be more visible to birds and may be an effective solution to the problem elicited by 
low light intensity and hence beneficial to bird welfare. They also found the latency of hens jumping from white perches was shorter than black or natural wood color perches in the lowest light intensity $(0.6$ lux $)$ in their study. In addition, Jones and Carmichael (1998) demonstrated hens spent less time jumping on white perches than black or yellow perches. For color preference, Jones and Carmichael (1998) found that hens showed a clear color preference in that they would like to approach and peck white or yellow bunches of string more readily and frequently than orange or blue ones. However, no study has been conducted on preference for perch color. Besides, there is little information regarding hens general behaviors and perching behaviors under different group size (stocking density), or perch color preference difference between individual and groups of hens. Therefore, the objective of the present study was to investigate the general and perching behaviors of laying hens under different group size (stocking density), and to test the perch color (white, black and brown) preference of hens during night.

\section{MATERIALS AND METHODS}

\section{Animals and management}

Total 390 Hyline Brown laying hens were used in this experiment. The hens were reared commercially in conventional wire cages $(192 \mathrm{~cm}$ width $\times 37 \mathrm{~cm} \mathrm{depth \times 35}$ cm height) until 20 weeks of age and then were transferred to the experimental room. The experiment started at 20 weeks of age and ended at $31 \mathrm{wk}$. The experimental room was environmentally controlled and accommodated six pretest cages and another six test cages equipped with the designed perches. Feed and water were available ad libitum. Ambient temperature was maintained at $20 \pm 1{ }^{\circ} \mathrm{C}$ and relative humidity was maintained at $65 \%$ to $70 \%$. Light schedule was $16 \mathrm{~h} \mathrm{L:8} \mathrm{h} \mathrm{D} \mathrm{and} \mathrm{light} \mathrm{onset} \mathrm{was} \mathrm{at} \mathrm{4:30} \mathrm{am.}$ The illumination intensity was about 10 lux.

\section{Experimental design}

Experiments were conducted in six test cages (Figure 1) which were arranged in two rows across a broad central passage way in the test room. In order to avoid visual communication among hens, the lateral and back sides of the test cages were enclosed with black cloth. The test cages were $120 \mathrm{~cm} \times 80 \mathrm{~cm} \times 65 \mathrm{~cm}$ (width $\times$ depth $\times$ height) and were simultaneously equipped with three rectangular perches of different color: white, black and brown (natural wood color). The perch colors were created by spraying painting on wood. Each perch was $3.5 \mathrm{~cm}$ wide, $40 \mathrm{~cm}$ long and was positioned $25 \mathrm{~cm}$ high above the wire mesh floor and $30 \mathrm{~cm}$ away from the back side of the cage. They were positioned parallel to the feeder trough and arranged in a line across the cage. The arranging order of the perches was randomly and rotated weekly in each test cage to avoid a position effect. The feed trough was fixed in front of the test cages and cameras with an infrared light source were fixed at the opposite site of the cages. The stocking density for individual and group test was 1.04 hens per $\mathrm{m}^{2}$ in G1 group, 4.17 hens per $\mathrm{m}^{2}$ in $\mathrm{G} 4$ group, 8.33 hens per $\mathrm{m}^{2}$ in G8 group, respectively.

\section{Protocol}

This study was divided into three levels of preference test: individual test (G1), group test of four hens (G4) and group test of eight hens (G8). In the individual test, six laying hens were randomly selected from the conventional cages (original groups) and assigned at random to each of the six test cages. After four days of habituation, hens were

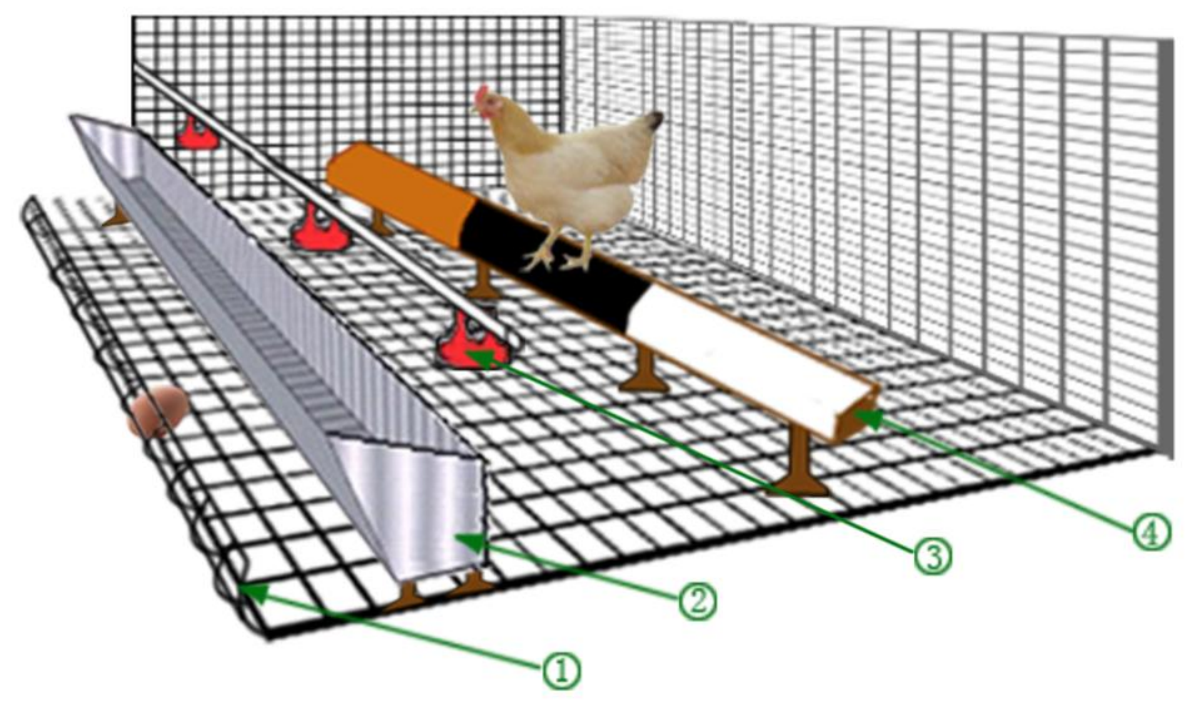

Figure 1. Test cages with three colored perches (other enclosing wire walls have been omitted from the drawing): (1) egg trough; (2) feed trough; (3) nipple drinker; (4) perch. 
tested and recorded at the fifth day. Then the hens were removed from the test cages and withdrawn from the experiment. When these hens were taken away, another six hens were randomly allocated to the test cages following the same procedure as the earlier test. This procedure was replicated five times. After individual tests, group tests were followed. Six groups of four hens were randomly selected from the conventional cages (original groups) and were assigned to six pre-test cages (the cages without perches) for seven days to establish social ranking, and then each group was assigned at random to each of the six test cages. As in the individual test, the hens were tested and recorded at the fifth day after four habituating days. Then the hens were removed after the test. Also, this procedure was repeated five times. The group of eight hens was tested following four hens group test. The procedure was same as that of four hens test. In total, there were 30 replicates in each individual tests and group tests.

\section{Data collection}

The hens were individually marked by spraying dyes on different parts of their body in the group tests for ease of individual identification. In G4 groups, the hens were marked at their head, body, wing or tail, respectively. While in G8 groups, the hens were respectively marked at their head, body, wing, tail, head plus body, head plus tail, head plus wing or body plus wing. After four habituating days, hens behaviors were filmed during the following periods: $8: 00$ to $10: 00 ; 14: 00$ to $16: 00 ; 19: 00$ to $21: 00 ; 23: 30$ to $0: 30$ on the fifth day using video cameras (FS-EH303, Shenzhen Feihongxin technology company, Shenzhen, China) with infrared light sources switched on during night.

Video recording was analyzed by scan sampling and instantaneous sampling for the general behaviors of hens on the wire floor using "The Observer" (Version 5.0, Noldus Information Technology BV, Wageningen, The Netherlands). For the perching behaviors, continuous recording and focal sampling was used for the hens on the perches during the period of $8: 00$ to $10: 00 ; 14: 00$ to $16: 00 ; 19: 00$ to $21: 00$. All the behavior patterns, as defined in Table 1, were analyzed. The general behaviors were divided into two categories. One is general state behaviors which included feeding,

Table 1. Behavioral categories and definitions

\begin{tabular}{|c|c|}
\hline Behavioral categories & Definitions \\
\hline \multicolumn{2}{|l|}{ General state behaviors } \\
\hline Feeding & Hen directs its beak to feed trough and carries out pecking or eating, once or repeatedly \\
\hline Walking & Hen raises one of its legs with the other leg standing on floor and moves forward \\
\hline Sitting & Hens' abdomen contacts with the floor and both legs are twisted under the body \\
\hline Standing & Both legs are strengthened on the floor \\
\hline Perching & All behaviors exhibited when the hens are on perches \\
\hline \multicolumn{2}{|l|}{ General event behaviors } \\
\hline Drinking & Hen directs its beak to nipple drinker and raises its head when getting water \\
\hline Preening & $\begin{array}{l}\text { Hen directs its beak to its own plumage of several body parts (thorax, abdomen, shoulder, interior } \\
\text { and exterior wings, rumps, back, and cloaca) and carries on pecking, nibbling, combing or rotating } \\
\text { movements, once or repeatedly (Pickel et al., 2010) }\end{array}$ \\
\hline Staring & Hens' head stays immovability with its eyes open \\
\hline Exploring & Hens' beak pecking at the floor or perch \\
\hline Social behavior & Behavior happens between two or more hens including pecking or contacting \\
\hline Comforting behavior & $\begin{array}{l}\text { Behavior including scratching, body shaking, tail shaking, wing flapping, wing-leg-stretching and } \\
\text { wing lifting (Pickel et al., 2010) }\end{array}$ \\
\hline Perching state behaviors & State behaviors happened on perches \\
\hline Standing & Both legs are strengthened on perches \\
\hline Sitting & $\begin{array}{l}\text { Hens' body is on perch, and its abdomen contacts with the perch and both legs are twisted under the } \\
\text { body }\end{array}$ \\
\hline Walking & Hen raises one of its legs with the other leg standing on perch and moves forward \\
\hline Perching event behaviors & Event behaviors happened on perches \\
\hline Preening & Preening behavior when hens on perches \\
\hline Staring & Staring behavior when hens on perches \\
\hline Exploring & Exploring behavior when hens on perches, most is pecking at the perch \\
\hline Comforting behavior & Comfort behaviors happened on perch \\
\hline Transferring & Hens walking or jumping from one perch to another \\
\hline Jumping up and down & Hens transferring or jumping from perches to floor or from floor to perch \\
\hline
\end{tabular}


Table 2. Comparison of general state behaviors of different treatments in different time periods $(\mathrm{n}=30)$

\begin{tabular}{|c|c|c|c|c|c|c|c|c|c|}
\hline \multirow{2}{*}{ Behavior (\%) } & \multicolumn{3}{|c|}{ Group size } & \multicolumn{3}{|c|}{ Time period } & \multirow{2}{*}{ SEM } & \multicolumn{2}{|c|}{ p-value } \\
\hline & G1 & G4 & G8 & Morning & Afternoon & Evening & & Group & Period \\
\hline Feeding & $36.30^{\mathrm{a}}$ & $25.86^{\mathrm{b}}$ & $27.04^{\mathrm{b}}$ & $40.15^{\mathrm{d}}$ & $36.29^{\mathrm{d}}$ & $12.76^{\mathrm{e}}$ & 1.62 & $* * *$ & $* * *$ \\
\hline Standing & $10.98^{\mathrm{b}}$ & $13.70^{\mathrm{b}}$ & $19.15^{\mathrm{a}}$ & $18.39^{\mathrm{d}}$ & $18.23^{\mathrm{d}}$ & $7.21^{\mathrm{e}}$ & 1.11 & $*$ & $* * *$ \\
\hline Sitting & $8.68^{\mathrm{c}}$ & $15.10^{\mathrm{b}}$ & $21.22^{\mathrm{a}}$ & $11.35^{\mathrm{e}}$ & $14.23^{\mathrm{d}}$ & $19.42^{\mathrm{d}}$ & 1.89 & $* * *$ & $*$ \\
\hline Walking & $24.89^{\mathrm{a}}$ & $18.53^{\mathrm{b}}$ & $13.60^{\mathrm{c}}$ & $21.52^{\mathrm{d}}$ & $22.10^{\mathrm{d}}$ & $13.40^{\mathrm{e}}$ & 1.24 & $* * *$ & $* * *$ \\
\hline Perching & $19.15^{\mathrm{b}}$ & $26.81^{\mathrm{a}}$ & $19.00^{\mathrm{b}}$ & $8.59^{\mathrm{e}}$ & $9.15^{\mathrm{e}}$ & $47.21^{\mathrm{d}}$ & 2.37 & $*$ & $* * *$ \\
\hline
\end{tabular}

NS $=$ Not significant. $* \mathrm{p}<0.05$ and $* * \mathrm{p}<0.01$, and $* * * \mathrm{p}<0.001$.

${ }_{\mathrm{a}, \mathrm{b}, \mathrm{c}}$ Different letters within a row indicate significant differences among group sizes resulting from multiple comparisons.

${ }^{\mathrm{d}, \mathrm{e}}$ Different letters within a row indicate significant differences among time periods resulting from multiple comparisons.

standing, sitting, walking on the floor and perching on the perches, and the other is general event behaviors which included drinking, preening, staring, exploring, social behavior and comforting behavior. The perching behaviors on different colored perches were recorded separately and also divided into event behaviors and state behaviors. Behavior pattern was counted as a new event after being disrupted by other behavioral patterns or stopped for more than $10 \mathrm{~s}$. For the event behaviors, if it was presented longer than $30 \mathrm{~s}$, it was recorded as a new one. Observations showed that the hens resting position had no changes during 23:30 to 0:30, so during this period, only the location (cage floor or perch) of each individual hen (in G1, G4 and G8 groups) was recorded. When hens were found on perches, the color of perches was recorded. The total number of the hens selecting each perch color during the testing period was recorded.

\section{Statistical analysis}

The data was analyzed using the SPSS 17.0 software. Duration of the general state behaviors was given in percentage of time based on the total time observed, and data were tested for normal distribution (KolmogorovSmirnov test) and were subjected to arcsine transformation or arcsine square root transformation in order to obtain a normal distribution when necessary. The event behaviors were represented in frequencies (the total occurrences per hour) and were square root transformed to obtain a normal distribution when necessary. Data were subjected to the Repeated Analysis in Mixed Procedure to determine effects of group size (G1, G4 and G8) and time period (morning, afternoon and evening) on behavior differences. The group sizes and time periods were considered as fixed effects, and testing order was repeated factor as random effect. In case of significance, Tukey-Kramer Adjudgement method was used for multiple comparisons. Results were given in LSMeans with their standard errors (SE). Probability values less than 0.05 were considered as significant.

The perching behaviors on different colored perches of the hens in G1, G4 and G8 groups were recorded separately and divided into the state behaviors and the event behaviors.
The state behaviors were represented in percentages, while the event behaviors were represented in frequencies. Friedman Test in Nonparametric Test was used to compare the difference between each behavior and perching parameters on different perches. Data were presented as Means with standard deviation. Probability values less than 0.05 were considered as significant.

Furthermore, the proportion of the hens positions during mid-night was calculated and subjected to Chi-square analysis in Crosstabs procedure under Descriptive Statistics process. Probability values less than 0.05 were considered as significant.

\section{RESULTS}

\section{Effects of different group size and time period on general behaviors}

The results (Table 2) showed that the effects of group size (stocking density) on general state behaviors were significant. Feeding and walking were performed more $(\mathrm{p}<0.001)$, and sitting was less $(\mathrm{p}<0.001)$ in $\mathrm{G} 1$ groups. The hens in G4 groups spent more time perching than the hens in G1 and G8 groups $(\mathrm{p}<0.05)$. Different time periods had significant effects on feeding, standing, sitting, walking and perching behavior. Feeding, standing and walking behaviors were performed more $(\mathrm{p}<0.001)$ at daytime, whereas sitting $(\mathrm{p}<0.05)$ and perching behaviors were more at night $(\mathrm{p}<0.001)$.

The frequencies of drinking, preening, staring, comforting and social behavior on floor (Table 3) were significantly affected by group size $(\mathrm{p}<0.001)$. The hens in individual groups (G1) performed more drinking and preening behavior $(\mathrm{p}<0.001)$ compared to the hens in $\mathrm{G} 4$ and G8 groups. The social and comforting behavior were higher $(\mathrm{p}<0.001)$ in $\mathrm{G} 4$ groups than in G8 groups. Drinking, preening $(\mathrm{p}<0.001)$, staring $(\mathrm{p}<0.001)$ and social behavior $(\mathrm{p}<0.05)$ differed in different time periods. These behaviors were performed more at daytime than night.

\section{Perch color preference during mid-night}

The proportion of hens positions during night is 
Table 3. Comparison of general event behaviors of different treatments in different time periods $(\mathrm{n}=30)$

\begin{tabular}{|c|c|c|c|c|c|c|c|c|c|}
\hline \multirow{2}{*}{ Behavior $(/ \mathrm{h})$} & \multicolumn{3}{|c|}{ Group size } & \multicolumn{3}{|c|}{ Time period } & \multirow{2}{*}{ SEM } & \multicolumn{2}{|c|}{ p-value } \\
\hline & G1 & G4 & G8 & Morning & Afternoon & Evening & & Group & Period \\
\hline Drinking & $8.28^{\mathrm{a}}$ & $2.17^{\mathrm{b}}$ & $1.17^{\mathrm{b}}$ & 3.72 & 4.06 & 3.83 & 0.49 & $* * *$ & $* * *$ \\
\hline Preening & $16.11^{\mathrm{a}}$ & $11.39^{\mathrm{b}}$ & $14.00^{\mathrm{ab}}$ & $15.61^{\mathrm{d}}$ & $20.11^{\mathrm{d}}$ & $5.77^{\mathrm{e}}$ & 1.18 & $*$ & $* * *$ \\
\hline Staring & $23.27^{\mathrm{b}}$ & $19.05^{\mathrm{c}}$ & $27.05^{\mathrm{a}}$ & $27.78^{\mathrm{d}}$ & $30.61^{\mathrm{d}}$ & $11.00^{\mathrm{e}}$ & 1.25 & $* * *$ & $* * *$ \\
\hline Exploring & 9.11 & 8.67 & 9.55 & 10.11 & 8.27 & 8.94 & 0.74 & NS & NS \\
\hline Social behavior & $0.00^{\mathrm{c}}$ & $7.05^{\mathrm{a}}$ & $1.94^{\mathrm{b}}$ & $2.44^{\mathrm{e}}$ & $4.06^{\mathrm{d}}$ & $2.50^{\mathrm{e}}$ & 0.49 & $* * *$ & $*$ \\
\hline Comforting behavior & $2.55^{\mathrm{a}}$ & $3.56^{\mathrm{a}}$ & $1.22^{\mathrm{b}}$ & 2.06 & 2.17 & 3.11 & 0.41 & $* * *$ & NS \\
\hline
\end{tabular}

NS $=$ Not significant. $* \mathrm{p}<0.05$ and $* * \mathrm{p}<0.01$, and $* * * \mathrm{p}<0.001$.

a,b,c Different letters within a row indicate significant differences among group sizes resulting from multiple comparisons.

${ }^{\mathrm{d}, \mathrm{e}}$ Different letters within a row indicate significant differences among time periods resulting from multiple comparisons.

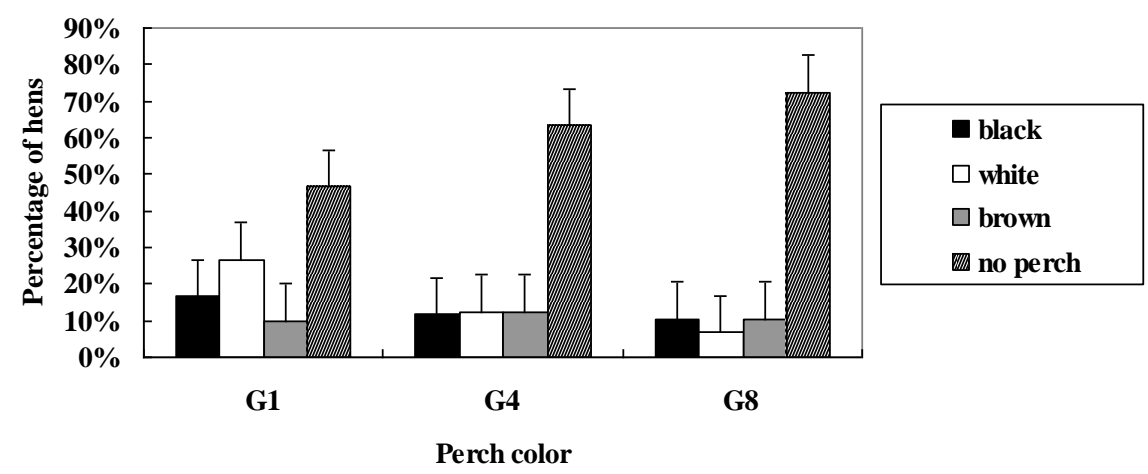

Figure 2. Proportion of different resting positions during night.

presented in Figure 2. The percentage of the hens choosing the floor to rest was greater in all groups. The proportion was $46.7 \%, 63.3 \%$ and $72.5 \%$ in G1, G4 and G8 groups, respectively. Whereas in the hens choosing perches the preference was different in three group sizes. Individual hens chose white perches most $(50.1 \%)$ and brown least $(18.7 \%)$. There was no particular color preference in G4 groups. However, the hens which chose perch to rest in G8 groups preferred black (37.8\%) and brown perches (37.8\%) to white ones $(24.4 \%)$. In general, no statistical difference was found in the preference of perch color in all groups $\left(\mathrm{G} 1: x^{2}=2.889, \mathrm{p}>0.05 ; \mathrm{G} 4: x^{2}=0.052, \mathrm{p}>0.05 ; \mathrm{G} 1: x^{2}=\right.$ $2.702, \mathrm{p}>0.05)$.

\section{Effects of perch color on perching behaviors}

With the single hens in G1 (Table 4), the frequency of transferring from one perch to another differed $(\mathrm{p}<0.05)$ among perches of different colors. The hens on black perches transferred most. Besides, the total time of perching was different in three colored perches $(p<0.05)$. The hens spent longer time on black perches. Staring behavior on brown perches was significantly greater $(p<0.05)$ than on black or white perches during night. In addition, the hens on black perches showed more standing and less sitting behavior.

In G4 groups (Table 5), the hens on white perches performed more standing $(\mathrm{p}<0.05)$ at daytime and more

Table 4. Comparison of perching behaviors of different treatments in individual groups (means \pm SD)

\begin{tabular}{|c|c|c|c|c|c|c|c|c|c|c|c|c|}
\hline \multirow{2}{*}{ Perching parameters } & \multicolumn{4}{|c|}{ Day } & \multicolumn{4}{|c|}{ Night } & \multicolumn{4}{|c|}{ On average } \\
\hline & Black & White & Brown & $\mathrm{p}$ & Black & White & Brown & $\mathrm{p}$ & Black & White & Brown & $\mathrm{p}$ \\
\hline Total time of perching $(\mathrm{min} / \mathrm{h})$ & $5.83 \pm 1.72$ & $5.00 \pm 3.29$ & $4.50 \pm 3.01$ & NS & $6.17 \pm 1.72$ & $5.12 \pm 3.36$ & $3.83 \pm 2.79$ & NS & $6.00 \pm 1.65$ & $5.06 \pm 3.21$ & $4.17 \pm 2.67$ & $*$ \\
\hline Frequency of transferring $(/ \mathrm{h})$ & $7.00 \pm 4.89$ & $2.38 \pm 2.07$ & $2.17 \pm 0.98$ & $*$ & $7.67 \pm 5.47$ & $2.38 \pm 1.99$ & $1.83 \pm 0.98$ & $*$ & $7.33 \pm 4.96$ & $2.38 \pm 1.96$ & $2.00 \pm 0.91$ & ** \\
\hline Number of jumping (/h) & $2.80 \pm 2.05$ & $2.17 \pm 1.94$ & $2.17 \pm 0.98$ & NS & $3.25 \pm 2.06$ & $2.75 \pm 0.22$ & $2.00 \pm 1.09$ & NS & $2.25 \pm 2.14$ & $1.50 \pm 1.93$ & $2.08 \pm 0.95$ & NS \\
\hline Standing $(\%)$ & $46.82 \pm 29.82$ & $28.96 \pm 23.45$ & $27.95 \pm 28.72$ & NS & $45.89 \pm 30.74$ & $30.42 \pm 25.05$ & $18.06 \pm 21.35$ & NS & $46.35 \pm 28.88$ & $29.69 \pm 23.45$ & $23.00 \pm 23.63$ & NS \\
\hline Walking (\%) & $7.50 \pm 11.73$ & $26.79 \pm 21.59$ & $10.53 \pm 11.74$ & NS & $0.00 \pm 0.00$ & $18.87 \pm 20.82$ & $4.17 \pm 10.21$ & NS & $3.75 \pm 8.82$ & $22.83 \pm 20.89$ & $7.35 \pm 10.54$ & NS \\
\hline Sitting (\%) & $45.68 \pm 31.12$ & $44.26 \pm 22.26$ & $61.52 \pm 30.75$ & NS & $54.11 \pm 30.74$ & $50.71 \pm 29.76$ & $77.78 \pm 19.48$ & NS & $49.90 \pm 29.82$ & $47.49 \pm 25.61$ & $69.65 \pm 24.87$ & NS \\
\hline Preening (/min) & $0.13 \pm 0.12$ & $0.09 \pm 0.09$ & $0.09 \pm 0.13$ & NS & $0.12 \pm 0.14$ & $0.09 \pm 0.11$ & $0.01 \pm 0.12$ & NS & $0.12 \pm 0.12$ & $0.09 \pm 0.09$ & $0.04 \pm 0.09$ & NS \\
\hline Staring (/min) & $0.16 \pm 0.09$ & $0.35 \pm 0.28$ & $0.35 \pm 0.25$ & NS & $0.12 \pm 0.15$ & $0.51 \pm 0.62$ & $0.63 \pm 0.70$ & $*$ & $0.14 \pm 0.12$ & $0.43 \pm 0.47$ & $0.49 \pm 0.49$ & $*$ \\
\hline Exploring (/min) & $0.28 \pm 0.18$ & $0.21 \pm 0.26$ & $0.18 \pm 0.16$ & NS & $0.35 \pm 0.21$ & $0.07 \pm 0.12$ & $0.26 \pm 0.39$ & NS & $0.31 \pm 0.19$ & $0.14 \pm 0.21$ & $0.22 \pm 0.27$ & NS \\
\hline Comforting behavior (/min) & $0.14 \pm 0.12$ & $0.24 \pm 0.23$ & $0.18 \pm 0.15$ & NS & $0.10 \pm 0.13$ & $0.19 \pm 0.15$ & $0.12 \pm 0.21$ & NS & $0.12 \pm 0.12$ & $0.22 \pm 0.19$ & $0.15 \pm 0.17$ & NS \\
\hline
\end{tabular}

NS $=$ Not significant. $* \mathrm{p}<0.05$ and $* * \mathrm{p}<0.01$, and $* * * \mathrm{p}<0.001$. 
Table 5. Comparison of perching behaviors of different treatments in 4-hen groups (means \pm SD)

\begin{tabular}{|c|c|c|c|c|c|c|c|c|c|c|c|c|}
\hline \multirow{2}{*}{ Perching parameters } & \multicolumn{4}{|c|}{ Day } & \multicolumn{4}{|c|}{ Night } & \multicolumn{4}{|c|}{ On average } \\
\hline & Black & White & Brown & $\mathrm{p}$ & Black & White & Brown & $\mathrm{p}$ & Black & White & Brown & $\mathrm{p}$ \\
\hline Total time of perching $(\mathrm{min} / \mathrm{h})$ & $8.36 \pm 6.88$ & $8.00 \pm 7.74$ & $8.08 \pm 4.15$ & NS & $6.85 \pm 4.51$ & $10.44 \pm 7.74$ & $5.50 \pm 4.15$ & NS & $7.63 \pm 5.80$ & $9.33 \pm 6.57$ & $6.74 \pm 4.76$ & NS \\
\hline Frequency of transferring $(/ \mathrm{h})$ & $2.21 \pm 2.11$ & $1.93 \pm 1.85$ & $2.08 \pm 1.34$ & NS & $1.31 \pm 0.85$ & $2.00 \pm 1.85$ & $1.50 \pm 0.34$ & * & $1.78 \pm 1.67$ & $1.97 \pm 1.83$ & $1.78 \pm 1.53$ & NS \\
\hline Number of jumping (/h) & $1.50 \pm 1.83$ & $2.40 \pm 1.69$ & $1.85 \pm 1.83$ & NS & $2.23 \pm 3.00$ & $2.44 \pm 1.69$ & $1.26 \pm 0.83$ & NS & $1.85 \pm 2.44$ & $2.42 \pm 1.69$ & $1.56 \pm 0.97$ & NS \\
\hline Standing $(\%)$ & $42.60 \pm 32.86$ & $59.07 \pm 28.19$ & $36.26 \pm 36.77$ & $*$ & $60.34 \pm 31.33$ & $40.83 \pm 28.19$ & $33.42 \pm 36.77$ & NS & $51.14 \pm 32.78$ & $49.12 \pm 29.71$ & $34.79 \pm 37.10$ & NS \\
\hline Walking (\%) & $28.15 \pm 31.23$ & $17.53 \pm 32.40$ & $33.22 \pm 35.02$ & NS & $20.69 \pm 22.38$ & $31.08 \pm 32.40$ & $24.21 \pm 35.02$ & NS & $24.55 \pm 27.08$ & $24.92 \pm 29.70$ & $28.55 \pm 31.08$ & NS \\
\hline Sitting $(\%)$ & $29.25 \pm 31.13$ & $23.40 \pm 29.93$ & $30.53 \pm 40.64$ & NS & $18.97 \pm 20.34$ & $28.09 \pm 29.93$ & $42.37 \pm 40.64$ & NS & $24.30 \pm 26.51$ & $25.96 \pm 25.43$ & $36.67 \pm 35.81$ & NS \\
\hline Preening (/min) & $0.14 \pm 0.18$ & $0.18 \pm 0.26$ & $0.06 \pm 0.30$ & NS & $0.12 \pm 0.20$ & $0.26 \pm 0.26$ & $0.27 \pm 0.31$ & NS & $0.13 \pm 0.24$ & $0.22 \pm 0.25$ & $0.17 \pm 0.26$ & NS \\
\hline Staring (/min) & $0.41 \pm 0.43$ & $0.32 \pm 0.25$ & $0.42 \pm 0.16$ & NS & $0.51 \pm 0.36$ & $0.27 \pm 0.25$ & $0.15 \pm 0.16$ & $*$ & $0.46 \pm 0.39$ & $0.29 \pm 0.29$ & $0.28 \pm 0.29$ & NS \\
\hline Exploring $(/ \mathrm{min})$ & $0.00 \pm 0.00$ & $0.04 \pm 0.10$ & $0.04 \pm 0.03$ & NS & $0.07 \pm 0.10$ & $0.05 \pm 0.10$ & $0.01 \pm 0.03$ & NS & $0.04 \pm 0.08$ & $0.05 \pm 0.09$ & $0.03 \pm 0.06$ & NS \\
\hline Comforting behavior (/min) & $0.06 \pm 0.16$ & $0.08 \pm 0.15$ & $0.03 \pm 0.08$ & NS & $0.00 \pm 0.00$ & $0.03 \pm 0.08$ & $0.01 \pm 0.04$ & NS & $0.03 \pm 0.12$ & $0.05 \pm 0.11$ & $0.02 \pm 0.06$ & NS \\
\hline
\end{tabular}

NS $=$ Not significant. $* \mathrm{p}<0.05$ and $* * \mathrm{p}<0.01$, and $* * * \mathrm{p}<0.001$.

frequent transferring $(\mathrm{p}<0.05)$ at night. Staring on black perches was greater $(\mathrm{p}<0.05)$ than on white or brown perches.

In G8 groups (Table 6), the frequency of jumping up and down from white perches was performed more than from others perches $(\mathrm{p}<0.05)$. The hens on white perches performed more standing and preening but with no statistical difference.

\section{DISCUSSION}

Effects of group size and time period on general behaviors on cage floor

Under high stocking density in commercial production, laying hens may restrict their behavior exhibition and thus may influence their welfare. As one of the most important factors in egg production, the changes of stocking density may affect behavior patterns of hens (Dawkins et al., 2004; Nelson, 2004). Appleby (2004) has suggested that minimum space allowances in furnished cages should vary with group size from at least $800 \mathrm{~cm}^{2}$ per bird in groups of eight or more, up to at least $900 \mathrm{~cm}^{2}$ for groups of three or fewer, plus a litter area. In the present study, the stocking density was 1.04 hens $/ \mathrm{m}^{2}, 4.17$ hens $/ \mathrm{m}^{2}$ and 8.33 hens $/ \mathrm{m}^{2}$ in $\mathrm{G} 1, \mathrm{G} 4$ and G8 groups, respectively. So the allowance for each hen was respectively $9,600 \mathrm{~cm}^{2}, 2,400 \mathrm{~cm}^{2}$ and $1,200 \mathrm{~cm}^{2}$ in $\mathrm{G} 1$, G4 and G8 groups. The space allowance in this study was much greater than that in conventional cages $\left(450 \mathrm{~cm}^{2}\right.$ to $550 \mathrm{~cm}^{2}$ for each hen) and even in furnished cages $\left(750 \mathrm{~cm}^{2}\right.$ for each hen). We believe this stocking density can meet the requirements of hens behavior exhibition.

The results in this study showed that general behaviors except exploring were significantly affected by the group size (stocking density). The hens in individual groups performed more feeding, walking, comforting behavior and less sitting behavior. This can be easily understood because single hens in cages had more individual space which allowed them to be more active. In our study, comforting behavior was performed more in individual and four hen groups than in the eight hen groups. The larger space allowance in these groups, as a result of low stocking density, may have alleviated the adverse effects of environment, and allowed comforting behaviors to be performed more frequently. In addition, the social behavior and perching time were greater in G4 groups than in G8 groups. A reason why social behavior and perching time did not increase with group size may be that the hens had already established stable social hierarchies in the larger groups, thus the social factors may have influenced perch use. Olsson and Keeling (2000) found half of testing hens did not want to work a push-door to get access for a perch if there was already one hen on perch. In our study, we also observed the situation that two or more hens simultaneously on perches was much less than one hen on perch, but the

Table 6. Comparison of perching behaviors of different treatments in 8-hen groups (means \pm SD)

\begin{tabular}{|c|c|c|c|c|c|c|c|c|c|c|c|c|}
\hline \multirow{2}{*}{ Perching parameters } & \multicolumn{4}{|c|}{ Day } & \multicolumn{4}{|c|}{ Night } & \multicolumn{4}{|c|}{ On average } \\
\hline & Black & White & Brown & $\mathrm{p}$ & Black & White & Brown & $\mathrm{p}$ & Black & White & Brown & $\mathrm{p}$ \\
\hline Total time of perching $(\mathrm{min} / \mathrm{h})$ & $5.75 \pm 5.04$ & $7.22 \pm 3.89$ & $6.26 \pm 4.15$ & NS & $10.20 \pm 10.04$ & $8.20 \pm 5.97$ & $5.08 \pm 4.21$ & NS & $7.66 \pm 7.79$ & $7.67 \pm 4.93$ & $5.78 \pm 4.14$ & NS \\
\hline Frequency of transferring $(/ \mathrm{h})$ & $2.65 \pm 2.01$ & $3.74 \pm 2.65$ & $3.63 \pm 2.49$ & NS & $2.87 \pm 2.26$ & $3.15 \pm 1.79$ & $2.69 \pm 2.09$ & NS & $2.74 \pm 2.09$ & $3.47 \pm 2.28$ & $3.25 \pm 2.36$ & NS \\
\hline Number of jumping (/h) & $0.80 \pm 0.62$ & $1.26 \pm 0.75$ & $1.16 \pm 0.83$ & NS & $0.93 \pm 0.70$ & $1.15 \pm 0.49$ & $0.77 \pm 0.44$ & NS & $0.86 \pm 0.65$ & $1.21 \pm 0.64$ & $1.00 \pm 0.72$ & $*$ \\
\hline Standing $(\%)$ & $39.14 \pm 27.05$ & $41.97 \pm 29.90$ & $33.48 \pm 20.09$ & NS & $39.49 \pm 19.43$ & $36.05 \pm 26.30$ & $18.68 \pm 15.97$ & NS & $39.29 \pm 23.76$ & $39.21 \pm 28.11$ & $27.47 \pm 19.69$ & NS \\
\hline Walking (\%) & $3.63 \pm 8.33$ & $5.22 \pm 13.34$ & $8.21 \pm 19.98$ & NS & $21.79 \pm 28.45$ & $13.82 \pm 20.02$ & $18.68 \pm 15.97$ & NS & $11.42 \pm 21.33$ & $9.22 \pm 17.13$ & $12.11 \pm 23.72$ & NS \\
\hline Sitting $(\%)$ & $57.23 \pm 25.97$ & $52.81 \pm 30.71$ & $58.31 \pm 25.50$ & NS & $38.71 \pm 17.73$ & $50.13 \pm 28.78$ & $63.51 \pm 26.93$ & NS & $49.29 \pm 24.35$ & $51.56 \pm 29.51$ & $60.42 \pm 25.79$ & NS \\
\hline Preening (/min) & $0.18 \pm 0.20$ & $0.12 \pm 0.16$ & $0.15 \pm 0.20$ & NS & $0.24 \pm 0.19$ & $0.26 \pm 0.22$ & $0.15 \pm 0.22$ & NS & $0.21 \pm 0.20$ & $0.19 \pm 0.19$ & $0.15 \pm 0.20$ & NS \\
\hline Staring $(/ \mathrm{min})$ & $0.35 \pm 0.28$ & $0.30 \pm 0.24$ & $0.29 \pm 0.29$ & NS & $0.21 \pm 0.19$ & $0.27 \pm 0.26$ & $0.23 \pm 0.23$ & NS & $0.29 \pm 0.26$ & $0.29 \pm 0.25$ & $0.27 \pm 0.27$ & NS \\
\hline Exploring (/min) & $0.02 \pm 0.07$ & $0.06 \pm 0.21$ & $0.05 \pm 0.11$ & NS & $0.05 \pm 0.11$ & $0.05 \pm 0.10$ & $0.05 \pm 0.09$ & NS & $0.03 \pm 0.09$ & $0.05 \pm 0.17$ & $0.05 \pm 0.10$ & NS \\
\hline Comforting behavior $(/ \mathrm{min})$ & $0.07 \pm 0.16$ & $0.12 \pm 0.04$ & $0.08 \pm 0.17$ & NS & $0.05 \pm 0.09$ & $0.05 \pm 0.12$ & $0.12 \pm 0.28$ & NS & $0.06 \pm 0.13$ & $0.03 \pm 0.09$ & $0.10 \pm 0.21$ & NS \\
\hline
\end{tabular}

NS $=$ Not significant. $* \mathrm{p}<0.05$ and $* * \mathrm{p}<0.01$, and $* * * \mathrm{p}<0.001$. 
reason for this is still unknown. On the other hand, the opportunity for individual hens to see other hens using perches increased with group size. Some social factors, such as simulation, social facilitation (Rosemary and Estevez, 2001) and competition (Newberry et al., 2001) also may have effects on perch use. Consequently, the perch use did not increased with group size.

Furthermore, different time periods had significant effects on most general behaviors of laying hens. It is known that animal behaviors are regulated by circadian rhythm which may make the proportion of behaviors change at different times. Active behaviors such as standing and walking were expressed more during daytime, while passive behaviors such as sitting and perching were performed more during night. The reason why perches were more frequently used for roosting at night than during the day may be because hens have the motivation of using perches at night and this behavior would be exhibited if perches were provided in housing systems (Olsson and Keeling, 2002). Therefore, the utilization of perches at night was significantly higher than at daytime.

\section{Perch color preference of hens during night}

Bayne et al. (1991) believed preference tests allowed for some determination of what is attractive to animal. Previous studies showed that when presented with food of different colors, birds showed unlearned preferences for some colors and aversions towards others (Gentle, 1985; Guilford, 1990; Schuler and Roper, 1992). However, most studies focused on the feed or water, not for perch. In the study presented here, no preference was found for white, black or brown perches. In individual groups, the white perch was preferred. In G4 groups, the proportion of the hens choosing each of the three colors was the same. While in G8 groups, black and brown perches were more popular than white ones. However, there were no statistical differences between choices of perch color. Jones and Carmichael (1998) suggested hens clearly had color preference, as they preferred to approach and to peck white or yellow strings more than other colors. However, in our studies, it seemed that no special preference for perch color existed for laying hens. Furthermore, Taylor et al. (2003) suggested hens had no potential preference for perch color in high light intensity. Perch color was not an important factor in jumping between perches. But in the low light intensity (0.6 lux), white perches were better than black or natural wood perches because the hens jumped faster to white colored perches and more successfully with less vocalization compared to black or natural wood perches. These results might be due to the higher visibility of the white perch at the low light intensity (Taylor et al., 2003). However, in our study, no such predominance of white perches was found. It might be because the light intensity in this study was a little higher (10lux) so that all three colors of perches could be seen clearly by the hens. Moreover, in our study, the percentage of the hens roosting on perches during night was just about $50 \%$, lower than previous studies which showed the perches in cages were heavily used by the hens especially during nights and varied from $86 \%$ (Appleby, 1995 ) to $100 \%$ (Tauson, 1984). Early experience may have an effect on this low utilization of perches. In this study, the hens were reared in conventional cages without perches until they were transferred to the test cages at the $20 \mathrm{wk}$ of age. Although there were four habituating days, the hens may have been still unfamiliar with perches. Furthermore, the different housing management, experimental design and breeds can also make our results different from others. However, in our study, we found that the hens really have no preference for perch color: white, black or brown.

\section{Effects of perch color on perching behaviors}

Pickel et al. (2010) suggested that analyzing the details of perching behavior could provide useful information for the suitability of a particular perch, and could be used to assess and develop perch designs. Perches are used more for sitting and standing (Struelens et al., 2008). Although no difference was detected in the choice of three color perches, it was found in this study that the hens perching behaviors differed on different colored perches. In the present study, the frequency of the hens transferring between different perches was different in G1 groups. The hens on black perches showed more frequent transferring than others. Besides, the perch time was significantly higher on black perches than white or brown ones. The hens in G1 groups spent more time on black perches, but they chose white perches more for roosting at night although there was no statistical significant difference. It seems that we can not conclude the perch color preference by the perching time during daytime. There might be no correlation between perching performance at day and choice of resting position at night. In G4 groups, in contrast with single hens in G1 groups, the hens performed more standing at day and more frequent transferring at night on white perches, but the preference was same for three colors at night. In addition, the hens in G8 groups jumped more frequently up and down from white perches. The standing and preening was performed more on white perches, but the choice of white perches was lower than others during night. Taylor et al. (2003) observed hens spent less time jumping on white perches in low light intensity, but they did not study the difference between behaviors of the hens perching on them. In the study presented here, we found no correlations existed between perching behaviors during the day and resting positions at night. However, more studies are needed 
to be done for investigating the relationship between perching behavior and perch properties.

\section{CONCLUSION}

This can be concluded that the results of this study suggested that although group size (stocking density) had a significant effect on most of the general behaviors of laying hens, the hens in cages with the different group sizes did not show clear perch color preference during night. Consequently, the color may not be an important factor for perch preference by the caged hens.

\section{ACKNOWLEDGEMENTS}

The work was supported by the National Natural Science Foundation of China for this research project (No.31172246/C170110).

\section{REFERENCES}

Appleby, M. C. 1995. Perch length in cages for medium hybrid laying hens. Br. Poult. Sci. 36:23-31.

Appleby, M. C. 2004. What causes crowding? Effects of space, facilities and group size on behavior, with particular reference to furnished cages for hens. Anim. Welf. 13:313-320.

Bayne, K. A. L., J. K. Hurst and S. L. Dexter. 1991. Evaluation of the preference to and behavioral effects of an enriched environment on male rhesus monkeys. Lab. Anim. Sci. 42:3845.

Dawkins, M. S. and S. Hardie. 1989. Space needs of laying hens. Br. Poult. Sci. 30:413-416.

Dawkins, M. S., C. A. Donnelly and T. A. Jones. 2004. Chicken welfare is influenced more by housing conditions than by stocking density. Nature 427:342-344.

Foster, R. G. and B. K. Follett. 1985. The involvement of a rhodopsin-like photopigment in the photoperiodic response of the Japanese quail. J. Comp. Physiol. A. 157:519-528.

Gentle, M. J. 1985. Sensory involvement in the control of food intake in poultry. Proc. Nutr. Soc. 44:313-321.

Guilford, T. 1990. The secrets of aposematism: unlearned responses to specific colors and patterns. Trends Ecol. Evol. 5:323-323.

Hughes, B. O. and H. A. Elson. 1977. The use of perches by broilers in floor pens. Br. Poult. Sci. 18:715-722.

Hughes, B. O. and I. J. H. Duncan. 1972. The influence of strain and environmental factors upon feather pecking and cannibalism in fowls. Br. Poult. Sci. 13:525-547.
Jones, R. B. and N. L. Carmichael. 1998. Pecking at string by individually caged, adult laying hens: colour preferences and their stability. Appl. Anim. Behav. Sci. 60:11-23.

King-Smith, P. E. 1971. Special senses. In: Physiology and Biochemistry of the Domestic Fowl (Ed. D. J. Bell and B. M. Freeman). pp. 1039-1080. Academic Press, London, UK.

Lewis, P. D. and T. R. Morris. 2000. Poultry and colored light. World's Poult. Sci. J. 56:189-207.

Manser, C. E. 1996. Effects of lighting on the welfare of domestic poultry. Anim. Welf. 5:341-360.

Nelson, L. 2004. Feathers fly over welfare of hemmed in hens. Nature 427:275

Newberry, R. C., I. Estevez and L. J. Keeling. 2001. Group size and perching behaviour in young domestic fowl. Appl. Anim. Behav. Sci. 73:117-129.

Newberry, R. C. 1995. Environmental enrichment: increasing the biological relevance of captive environments. Appl. Anim. Behav. Sci. 44:229-243.

Olsson, I. A. and L. J. Keeling. 2000. Night-time roosting in laying hens and the effect of thwarting access to perches. Appl. Anim. Behav. Sci. 68:243-256.

Olsson, I. A. and L. J. Keeling. 2002. The push-door for measuring motivation in hens: laying hens are motivated to perch at night. Anim. Welf. 11:11-19.

Pickel, T., B. Scholz and L. Schrader. 2010. Perch material and diameter affects particular perching behaviors in laying hens. Appl. Anim. Behav. Sci. 127:37-42.

Prescott, N. B. and C. M. Wathes. 1999. Spectral sensitivity of domestic fowl Gallusg domestic. Br. Poult. Sci. 40:332-339.

Prescott, N. B. and C. M. Wathes. 2002. Light and how birds perceive their environment. Br. Poult. Sci. (Suppl.) 43:57-58.

Rosemary, P. R. and I. Estevez. 2001. Effects of density on perching behavior of broiler chickens. Appl. Anim. Behav. Sci. 71:127-140.

Schuler, W. and T. J. Roper. 1992. Responses to warning coloration in avian predators. Adv. Study Behav. 21:111-146.

Struelens, E., F. A. M. Tuyttens, L. Duchateau, T. Leroy, M. Cox, E. Vranken, J. Buyse, J. Zoons, D. Berckmans, F. Ödberg and B. Sonck. 2008. Perching behavior and perch height preference of laying hens in furnished cages varying in height, Br. Poult. Sci. 49:381-389.

Tauson, R. 1984. Effects of a perch in conventional cages for laying hens. Acta Agric. Scand. 34:193-209.

Taylor, P. E., G. B. Scott and S. P. Rose. 2003. Ability of laying hens to negotiate jumps between horizontal perches: effects of light intensity and perch color. Br. Poult. Sci. 44:S32-S33.

Taylor, P. E., G. B. Scott and S. P. Rose. 2003. The ability of domestic hens to jump between horizontal perches: effects of light intensity and perch color. Appl. Anim. Behav. Sci. 83:99108. 